Savunma Bilimleri Dergisi

The Journal of Defense Sciences

May1s/May 2018, Cilt/Volume 17, Sayi/Issue 1.

ISSN (Bas1l1) : 1303-6831 ISSN (Online): 2148-1776

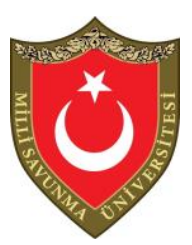

\title{
Hava Kuvvetleri Komutanlığı Malzeme İhtiyaç Planlaması Tedarik Tavsiye Listesinin ÇKKV Yöntemleri İle Analizi*
}

\author{
Uğur YAĞLI** ve Feyzan ARIKAN***
}

$\ddot{O} z$

Hava Kuvvetleri Komutanlığg'nın envanterindeki silah sistemlerini istenilen yerde ve miktarda faal olarak bulundurabilmesi; gerek barış zamanında düşman tehdit unsurları üzerinde caydırıcı olabilmesi açısından, gerekse kriz ve savaş zamanlarında etkin savunma yapabilmesi açısından kritik öneme sahiptir. Bu nedenle, silah sistemlerinin bakım ve arıza durumlarında kullanılan malzemeler için tedarik planlanmasının etkin şekilde yapılması zaruridir. Hava Kuvvetleri Komutanlığı, Malzeme Ihtiyaç Planlaması (MIP) için bir Karar Destek Sistemi (KDS) kullanmaktadır. KDS'nin oluşturduğu ihtiyaç listesi karar verici uzman personelce incelenmekte ve uygun görülen malzemeler için tedarik kararı verilmektedir. Bu çalışmada, en doğru tedarik kararının verilebilmesi için MIP sonuçlarının önem derecesine göre stralanarak karar vericilere inceleme faaliyetinde yol gösterecek bilimsel bir yaklaşım sunmak amaçlanmıştır. Bu amaç doğrultusunda, Çok Kriterli Karar Verme (ÇKKV) yöntemlerinden Technique for Order Preference by Similarity to Ideal Solution (TOPSIS) ve Analitik Hiyerarşi Prosesi (AHP) bütünleşik olarak kullanılmıştır. Sunulan yaklaşımın, geleneksel yöntem ile göz ardl edilen birçok malzemenin çok daha öncelikli olarak

\footnotetext{
* Bu çalışma, 2. Uluslararası Savunma Sanayii Sempozyumu, 6-8 Nisan 2017 Kırıkkale, Türkiye'de sunulmuştur.

** Hava Kuvvetleri Komutanlığı, Muhabere Elektronik ve Bilgi Sistemleri (MEBS) Bşk.lığı, 06580 Çankaya,Ankara

**** Doç.Dr., Gazi Ünv., Mühendislik Fak., Endüstri Müh. Böl., 06570, Maltepe, Ankara, farikan@gazi.edu.tr 
incelenmesine, olası birçok parça bekler olayı önlemeye ve kıt kaynakların verimli kullanılmasına katkı sunduğu, sıralama sonuçların kriter bazında analizi ve sonuçların kullanıcı tedarik kararları karşılaş̧tıılması ile tespit edilmiştir.

Anahtar Kelimeler: Kurumsal Kaynak Planlama, KKP, Malzeme Ihtiyaç Planlaması, MIP, Karar destek sistemi, Çok kriterli karar verme, ÇKKV, AHP, TOPSIS.

\title{
Analyzing Turkish Air Force Material Requirement Planning Procurement List Results Via MCDM Techniques
}

\begin{abstract}
It is crucially critical for the Air Force to be able to keep the weapons systems mission-capable in the inventory at their desired location and amount both in terms of being deterrent to the elements of the enemy threat in times of peace, and to ensure the country defense in times of crise and war. Hence, supply planning for the materials used in the maintenance and breakdown situations of the related systems has to be carried out effectively. Turkish Air Force utilizes a Decision Support System (DSS) that ensure the material requirement planning (MRP). The material-purchase-list established by the DSS is examined by the specialist staff to make the supply decision. The purpose of the study is to provide a scientific approach which will guide decision makers in the examination activity, by ranking the MRP results according to the importance level in order to give the most accurate procurement decision. To serve the aim of the study, Technique for Order Preference by Similarity to Ideal Solution (TOPSIS) and Analytic Hierarchy Process (AHP) which are Multi Criteria Decision Making (MCDM) method were performed in an integrated manner. The ranking order was evaluated based on each criterion and, also it was compared with the Staff's decisions in the considered past period. Based on these two analysis it is concluded that the utilized
\end{abstract}


Hava Kuvvetleri Komutanlığı Malzeme İhtiyaç Planlaması

Tedarik Tavsiye Listesinin ÇKKV Yöntemleri İle Analizi

integrated technique provides opportunity for experts to examine the purchased items primarily that might be ignored via traditional approach; prevent to exceed the possible deadline for waiting parts and use scarce resources more effective.

Keywords: Enterprise Resource Planning, ERP, Material Requirement Planning, MRP, Decision Support Systems, Multiple Criteria Decision Making, MCDM, AHP, TOPSIS.

\section{Giriş}

İşletmelerin artan rekabet şartlarına uyumu, ancak karmaşık iş akışlarının doğurduğu yüksek orandaki bilginin hızlı ve doğru işlenmesi ve yönetilmesi ile mümkündür. Kurumsal Kaynak Planlaması (KKP) işletmelerde mal ve hizmet üretimi için kullanılan işgücü ekipman malzeme gibi kıt kaynakların en etkin kullanımını sağlamak üzere işletmenin tedarikten dağıtıma kadar tüm iş süreçlerini ve verilerini bilgisayar destekli yazılımlar ile bütünleşik bir veri tabanı kullanarak yöneten veri/bilgi yönetimi sistemi olarak bu amaca hizmet eder.

KKP kullanan işletmeler, belirledikleri amaçlara ulaşma ölçütü olarak; ürün teslimat zamanları, müşteri memnuniyeti, işletme giderleri gibi pek çok nicel ve nitel değişken kullanırlar. Savunma sektörünün özel hedefleri nedeniyle, askerî endüstride, bu değişkenlere ilave olarak; herhangi bir askerî birliğin, personel ve teçhizat açısından harbe hazır bulunuşluk durumunu ifade eden "harbe hazırlık seviyesi”nin dikkate alınması zaruridir. Nitel bir değişken olan harbe hazırlık seviyesi; zaman, yer ve temin edilme şartları açısından değişkenlik arz eder. $\mathrm{Bu}$ değişkenlik nedeniyle, harbe hazırlık amacına hizmet etmek üzere verilecek askerî tedarik kararları hem mali, hem de stratejik güvenlik açısıdan kritik sonuçlara sahiptir. Bu nedenle, "ihtiyacı doğru belirleme/doğru ihtiyacı belirleme" konusu, savunma sektöründe KKP'den beklenen faydalar listesinde ilk sırada yer alır. 
Gerek sivil, gerekse askerî endüstrilerde işletme amacına özel geliştirilmiş KKP uygulamaları ve Karar Destek Sistemleri (KDS) kullanılmaktadır. KDS'ler, insanların karar vermelerinde yardımcı olan bilgisayar tabanlı bilgi sistemlere denir. KDS'ler, verilerin ve modellerin beraberce etkin şekilde kullanımını sağlayarak karmaşık karar problemlerinin çözümünde karar vericiye katkıda bulunurlar. Hava Kuvvetleri Komutanlığı (Hv.K.K.lı̆̆ı)'nın KKP uygulaması, SAP tabanlı Hava Kuvvetleri Bilgi Sistemi (HvBS)'dir. Bilgi sistemi içerisinde, komutanlığın amaçlarına hizmet etmek üzere geliştirilmiş birçok KDS bulunmaktadır. $\mathrm{Bu}$ çalışmanın konusunu oluşturan malzeme tedarik tavsiye sonuçları, HvBS'de bulunan KDS'lerden "malzeme ihtiyaç planlaması (MIP) modülü” yardımı ile üretilmektedir. Yapılan çalışma ile Hv.K.K.lığı'nın envanterdeki silah sistemlerinin idame işletmesi için ihtiyaç duyulan malzemelere tedarik kararı aşamasında MIP sonuçlarının etkin şekilde değerlendirmesine yardımcı olacak bilimsel bir sıralama prosedürünün belirlenmesi hedeflenmiştir.

$\mathrm{Bu}$ hedef doğrultusunda; çalışmanın içeriği; literatür araştırması, metodoloji, sistemin ve problemin tanımı, uygulama ve sonuç bölümlerinden oluşmaktadır.

\section{Literatür Araştırması}

Literatür araştırması, SCI (Science Citation Index)'de yer alan çalışmalar ile kısıtlanmıştır. Sivil alanda ÇKKV Teknikleri kullanılarak verilen tedarik kararları ile ilgili detaylı literatür araştırmasına Yağlı (2017)'dan erişilebilir. Bu çalışmalar içerisinde özellikle KKP ile ilgili olanlar iki ana başlıkta sınıflandırılabilir: 1) KKP yazılımı seçiminde ÇKKV tekniklerini kullanan çalışmalar (örn. Ayag ve Ozdemir, 2007; Gürbüz vd., 2012; Kılıç vd., 2014), 2) KKP yazılımının uygulama sonrası performansının değerlendirilmesinde ÇKKV tekniklerini kullanan çalışmalar (örn. Shen vd., 2016). 
Hava Kuvvetleri Komutanlığı Malzeme İhtiyaç Planlaması

Tedarik Tavsiye Listesinin ÇKKV Yöntemleri İle Analizi

Askerî karar verme alanında ÇKKV tekniklerini kullanan çalışmaların; kapsam ve kullanılan yöntem nazarında kronolojik sırada özetine Tablo 1' de yer verilmiştir. Söz konusu çalışmalar konularına göre dört ana başlıkta incelenebilir: 1) Askerî teçhizat seçimi (Cheng, 1996; Cheng vd., 1999; Cheng, 1999; Wang vd., 2008; Arslan ve Aydın, 2009; Aydoğan vd., 2009; Lin ve Hung, 2011; Jiang vd., 2011; Sanchez-Lozana vd., 2015; Gazibey vd., 2015), 2) En uygun askerî tekniğin/planın/yerin belirlenmesi (Leeneer ve Pastijn, 2002; Farahani ve Asgari, 2007; Schubert ve Horling, 2014), 3) Askerî personelin liyakata göre stralanmast (Chang vd., 2007; Arslan ve Aydın, 2009), 4) Ülkelerin askerî harcamalarına yönelik yaptığı offset anlaşmalardan en uygun olanı belirleme (Lu ve Wang, 2011; Wang, 2012).

Çalışmalar içerisinde sadece ikisi (Wang vd. (2008) ve Sanchez-Lozano vd. (2015)), AHP ve TOPSIS yaklaşımını bütünleşik olarak kullanmaktadır. Fakat bu iki çalışma, "askerî uçak seçimi" konusunu ele almaktadır. Literatürde AHPTOPSIS bütünleşik yaklaşımını kullanan çalışmalar ile ilgili detaylı literatüre Arıkan ve Küçükce (2012) ve Arıkan ve Çıtak (2017) çalışmalarından erişilebilir.

Yukarıda belirtilen araştırma kısıtları dahilinde, gerek sivil gerekse askerî alanda, KKP tabanlı MiP sonuçlarının değerlendirilmesinde karar destek sistemine yardımcı olacak nitelikte ÇKKV yaklaşımlarını kullanan bir çalışmaya rastlanmamıştır. Belirtilen bu özellikleri ile gerçekleştirilen bu çalışma literatüre katkı sağlamaktadır. 
Tablo 1. ÇKKV Tekniklerinin Askerî Alanda Kullanımı İle İlgili Çalışmalar

\begin{tabular}{|c|c|c|c|}
\hline & Referans & Kapsam & Kullanılan Yöntem \\
\hline 1 & Cheng (1996) & $\begin{array}{l}\text { Deniz altı füze sistemi } \\
\text { seçimi }\end{array}$ & Bulanık-AHP \\
\hline 2 & Cheng vd. (1999) & Saldırı helikopteri seçimi & Bulanık-AHP \\
\hline 3 & Cheng (1999) & Silah seçimi & $\begin{array}{l}\text { Sentetik Değerlendirme } \\
\text { Metodu. }\end{array}$ \\
\hline 4 & $\begin{array}{l}\text { Leeneer ve Pastijn } \\
(2002)\end{array}$ & $\begin{array}{l}\text { Mayın tespit tekniğinin } \\
\text { belirlenmesi }\end{array}$ & $\begin{array}{l}\text { ORESTE ve } \\
\text { PROMETHEE }\end{array}$ \\
\hline 5 & $\begin{array}{l}\text { Farahani ve Asgari } \\
(2007)\end{array}$ & $\begin{array}{l}\text { Askerî ikmal depolarının } \\
\text { yerlerinin belirlenmesi }\end{array}$ & TOPSIS \\
\hline 6 & Chang vd. (2007) & $\begin{array}{l}\text { Askerî personelin } \\
\text { liyakatlarına göre sıralaması }\end{array}$ & $\begin{array}{l}\text { Lee and Li'nin Bulanik } \\
\text { ortalama/yay1lım ve } \\
\text { metric uzakl1k metodu }\end{array}$ \\
\hline 7 & Wang vd. (2008) & $\begin{array}{l}\text { En uygun savaş uçağının } \\
\text { seçilmesi }\end{array}$ & Bulanık-AHP ve TOPSIS \\
\hline 8 & Aydogan vd. (2009) & Hafif makineli silah seçimi & ANP \\
\hline 9 & $\begin{array}{l}\text { Arslan ve Aydın } \\
(2009)\end{array}$ & $\begin{array}{l}\text { Askerî personel için en } \\
\text { uygun tayin yeri belirleme } \\
\text { ile silah seçimi }\end{array}$ & $\begin{array}{l}\text { Ideal and Anti-ideal } \\
\text { Algoritmas1 ve Siralama } \\
\text { Methodu }\end{array}$ \\
\hline 10 & Lu ve Wang (2011) & $\begin{array}{l}\text { Ülkelerin yapacağı offset } \\
\text { anlaşmalardan en uygun } \\
\text { olanın belirlenmesi }\end{array}$ & Bulanık-AHP \\
\hline 11 & Lin ve Hung (2011) & İnsansız Hava Aracı seçimi & $\begin{array}{l}\text { Bulanık Ağırlıklı } \\
\text { Ortalama }\end{array}$ \\
\hline 12 & Jiang vd. (2011) & $\begin{array}{l}\text { Silah sistemlerinin } \\
\text { kabiliyetlerini belirleme }\end{array}$ & $\begin{array}{l}\text { İnanç Fonksiyonları } \\
\text { modeli }\end{array}$ \\
\hline 13 & Wang (2012) & $\begin{array}{l}\text { Ülkelerin yapacağı offset } \\
\text { anlaşmalardan en uygun } \\
\text { olanın belirlenmesi } \\
\end{array}$ & ANP ve DEMATEL \\
\hline 14 & $\begin{array}{l}\text { Schubert ve Hörling } \\
\text { (2014) }\end{array}$ & $\begin{array}{l}\text { En iyi askerî savunma } \\
\text { planının belirlenmesi }\end{array}$ & $\begin{array}{l}\text { Pareto Optimal Sinır } \\
\text { Metodu }\end{array}$ \\
\hline 15 & $\begin{array}{l}\text { Sánchez-Lozano vd. } \\
(2015)\end{array}$ & $\begin{array}{l}\text { Tedarik edilecek eğitim } \\
\text { uçağının seçimi }\end{array}$ & Bulanık-AHP ve TOPSIS \\
\hline 16 & Gazibey vd. (2015) & Tank tedariği & DEMATEL \\
\hline
\end{tabular}


Hava Kuvvetleri Komutanlığı Malzeme İhtiyaç Planlaması

Tedarik Tavsiye Listesinin ÇKKV Yöntemleri İle Analizi

\section{Metodoloji}

Hv.K.K.lığı tedarik kararlarında kullanılmak üzere, homojen olmayan birimlerle ölçülen farklı kriterlerin aynı anda değerlendirilebilmesi ve planlı sipariş listesinde yer alan malzemenin ilgili kriterler nazarında önem sırasına konulması amaçlanmaktadır. Bu nedenle, kriterlerin değerlendirilmesinde, uzman personelin bilgilerini, tecrübelerini ve tercihlerini ifade etmesine imkan tanıdığı için AHP (Figueria vd., 2005; Can ve Arıkan, 2014) yönteminden faydalanılmıştır. Sıralaması yapılacak malzemenin çok farklı tipte olması nedeniyle, ideal çözümlere yakınlık yoluyla alternatifleri üstünlük ilişkisine göre sıralayan TOPSIS yönteminin kullanılmasına karar verilmiştir.

Bu çalışmada, KOBİ yöneticilerinin uzmanlıkları, bilgileri, tecrübeleri ve tercihlerini ifade etmesine imkan tanıyan sübjektif kriter ağırlıkları, probleme yön veren önemli bir bilgi kaynăğ olduğundan AHP [18, 19] yönteminden faydalanılarak gerçekçi sayısal verilere dönüştürülmüştür.

\section{Analitik Hiyerarşi Prosesi (AHP)}

1965 yılında L. Thomas Saaty (1990) tarafindan geliştirilen AHP, bu çalışma kapsamında kriter ağırlıklarını belirlemek üzere kullanılmıştır. AHP'nin 5 temel adımı aşağıdaki gibidir (Can ve Arıkan, 2014):

Adım 1. Problem ortaya konur, hedef belirlenir.

Adım 2. Kriter hiyerarşisi oluşturulur.

Adım 3. İkili karşıllaştırma matrisi oluşturulur.

Adım 4. Göreli önem vektörü (ağırlık vektörü) bulunur.

Adım 5. Tutarlılık oranı hesaplanır. Tutarlı olmama durumunda ikili karşılaştırmalar tekrar gözden geçirilerek işlemler tekrarlanır. 
TOPSIS (Technique for Order Preference by Similarity to Ideal Solution)

TOPSIS, Hwang ve Yoon (1981) tarafından geliştirilmiş bir sıralama tekniğidir. TOPSIS yöntemi 6 adımdan oluşur (Hwang ve Yoon, 1981; Shih vd., 2007):

Adım 1. Karar Matrisinin, D, Oluşturulması: $A_{k}, k=1,2, \ldots, n$ karar noktalarını (alternatifleri); $X_{j}, \quad j=1,2, . ., m$ kriterleri belirtmek üzere, karar matrisi $D=\left[x_{k j}\right]$ oluşturulur. $x_{k j} k$. alternatifinin $j$. kriter için aldığı performans değerini belirtir.

Adım 2. Vektör Normalizasyon İşlemi ile Standart Karar Matrisinin (R) Oluşturulması: $R=\left[r_{k j}\right]$, olmak üzere $r_{k j}$ aşağıdaki Eş. 1. kullanılarak hesaplanır.

$$
r_{k j}=\frac{x_{k j}}{\sqrt{\sum_{k=1}^{n} x_{k j}^{2}}}, \quad k=1,2, \ldots, n ; j=1,2, . ., m
$$

Adım 3) Ăgırlıkl Standart Karar Matrisinin (V) Oluşturulması:Kriterlere ilişkin ağırlık değerleri $w=\left\{w_{j}, j=1,2, . ., m\right\}$ ve $\sum_{j} w_{j}=1$ olmak üzere, ağırlıklı standart değer Eş. 2 ile hesaplanır.

$$
v_{k j}=w_{j} r_{k j}, k=1,2, \ldots, n ; j=1,2, . ., m
$$

Adım 4. İdeal $\left(A^{*}\right)$ ve Negatif İdeal ( $\left.A^{-}\right)$Çözümler: Eş. (3) ve (4) ile hesaplanır. Her iki formülde de $J_{1}$ fayda (maksimizasyon), $J_{2}$ ise kayıp (minimizasyon) kriterlerini belirten kümelerdir.

$$
\begin{aligned}
& A^{*}=\left\{\left(\max _{k} v_{k j} \mid j \in J_{1}\right),\left(\min _{k} v_{k j} \mid j \in J_{2}\right) \mid k=1,2, \ldots, n\right\}=\left\{v_{1}^{*}, v_{2}^{*}, \ldots, v_{m}^{*}\right\} \\
& A^{-}=\left\{\left(\min _{k} v_{k j} \mid j \in J_{1}\right),\left(\max _{k} v_{k j} \mid j \in J_{2}\right) \mid k=1,2, \ldots, n\right\}=\left\{v_{1}^{-}, v_{2}^{-}, \ldots, v_{m}^{-}\right\}
\end{aligned}
$$

Adım 5. İdeal Ayırım ( $\left.S_{k}^{*}\right)$ ve Negatif İdeal Ayırım ( $\left.S_{k}^{-}\right)$Ölçülerinin Hesaplanması: Ayrım ölçüleri her bir alternatifin ideal çözümden pozitif ve negatif sapma değerlerinin Euclidian Uzaklık cinsinden hesabıdır. Hesaplanma Eş. (5) ve (6) ile gösterilmiştir.

$$
S_{k}^{*}=\sqrt{\sum_{j=1}^{m}\left(v_{k j}-v_{j}^{*}\right)^{2}}, \quad k=1,2, \ldots, n
$$


Hava Kuvvetleri Komutanlığı Malzeme İhtiyaç Planlaması

Tedarik Tavsiye Listesinin ÇKKV Yöntemleri İle Analizi

$$
S_{k}^{-}=\sqrt{\sum_{j=1}^{m}\left(v_{k j}-v_{j}^{-}\right)^{2}}, \quad k=1,2, \ldots, n
$$

Adım 6. İdeal Çözüme Göreli Yakınlığın $\left(C_{k}^{*}\right)$ Hesaplanması ve Sıralama: $C_{k}^{*}=1$ değeri ilgili alternatifin ideal çözüme, $C_{k}^{*}=0$ değeri ise ilgili alternatifin negatif ideal çözüme mutlak yakınlığını gösterir.

$$
C_{k}^{*}=\frac{S_{k}^{-}}{S_{k}^{-}+S_{k}^{+}} \quad k=1,2, \ldots, n, 0 \leq C_{k}^{*} \leq 1
$$

\section{Sistemin ve Problemin Tanımı}

$\mathrm{Bu}$ çalışma, Hv.Loj.K.lığı'nın Hava Kuvvetleri Bilgi Sistemi (HvBS) olarak geliştirilen/yönetilen KKP bilgi sistemi ve onun alt bileşenlerinden MiP programı çıktıları ile ilgilidir. Hv.K.K.ığı, minimum maliyet ile harbe hazırlık seviyesini maksimum tutacak şekilde, envanterindeki harp araç ve gereçlerinin idame işletmesinden sorumludur. Hv.K.K.lı̆̆ı'nın idame işletmeye yönelik malzeme ihtiyaçlarının belirlenmesinde MiP tarafından oluşturulan tedarik tavsiye listesi uzman personelce incelenmekte ve tedarik kararları verilmektedir. Uzman personelin iş kutusuna düşen planlı siparişlerin arasında bir önem sırası veya grup bulunmamaktadır. Personel siparişleri bilgi ve tecrübesi nezdinde önceliklendirmekte ve değerlendirmektedir. Hatalı tedarik kararları zaman ve maliyet açısından risklidir. Uzman personelin etkin kararlar alabilmesi için, sahip olduğu kısıtlı zaman içerisinde KDS sonuçlarının değerlendirmesinde kendisine yardımcı olacak, standart ve bilimsel bir yaklaşım sağlayarak, insan kaynaklı hataları asgariye indirecek bir sıralama yöntemine ihtiyaç olduğu belirlenmiştir.

HvBS'de malzeme tanımlama ve kataloglama için NATO üyesi ülkelere ait standart sayısal kod NSN (Nato Stock Number) kullanılmaktadır. Bu çalışmanın kapsamı malzeme miktarı değil; her bir NSN'in tedarik edilip edilmeme durumu ile ilgilidir. Hv.K.K.lığından alınan izin kapsamında, içeriği tamamen aynı kalmak 
üzere, NSN isimleri gerçek hali anlaşılmayacak şekilde karıştırılarak kullanılmıştır. NSN'lerin fiyat bilgisi olarak malzeme birim fiyatları alınmıştır.

\section{Uygulama}

Problemin çözümü için AHP-TOPSIS yöntemlerinin adımlarının probleme yönelik entegrasyonu akış şeması olarak Şekil 1'de özetlenmiştir. Problemin tanımından sonraki adım, "probleme etki eden kriterlerin belirlenmesi ve kriterlerin ölçeklendirilmesi”dir.

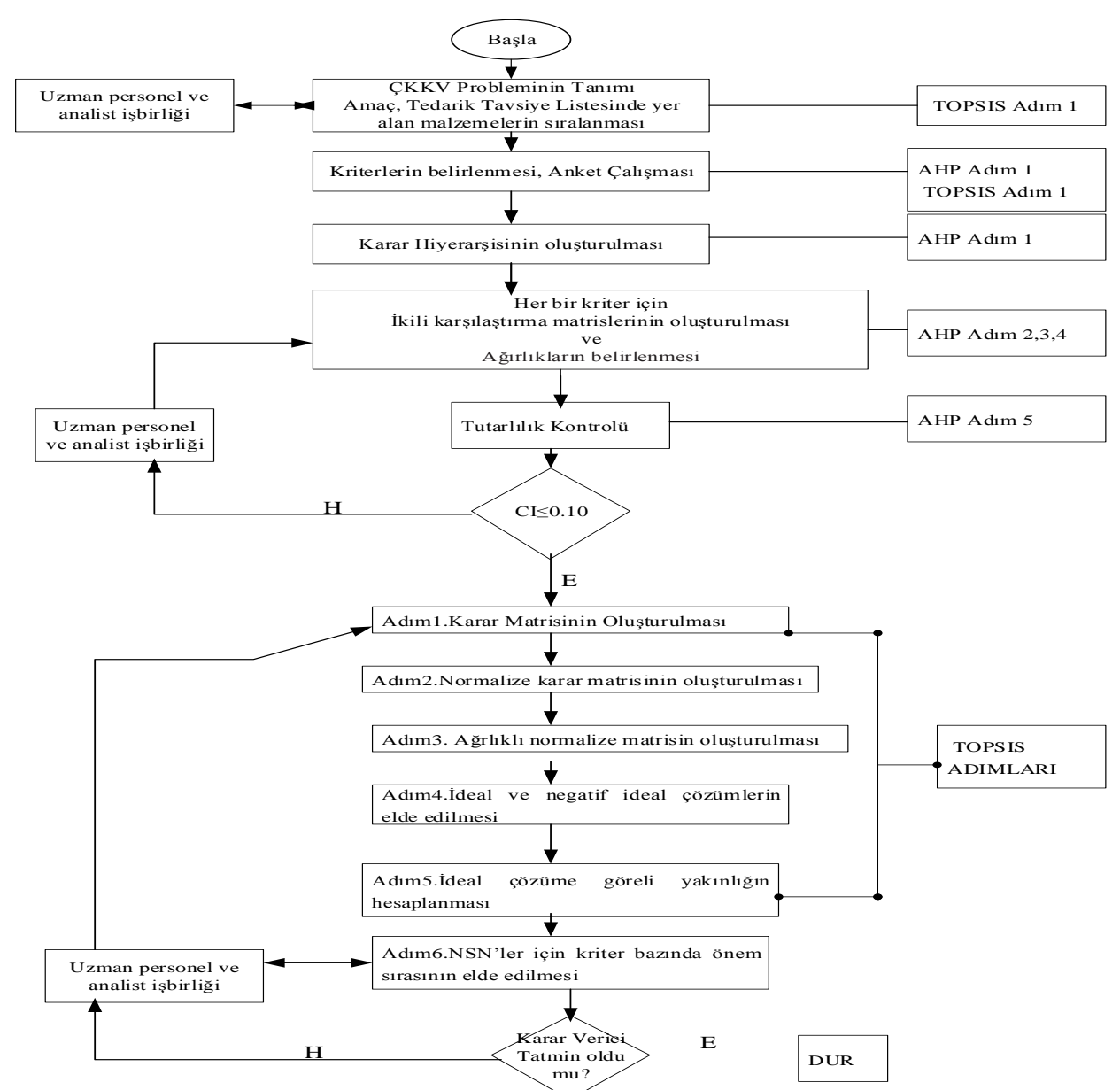

Şekil 1. AHP-TOPSIS bütünleşik yaklaşımının probleme adapte edilmiş adımları 
Hava Kuvvetleri Komutanlığı Malzeme İhtiyaç Planlaması

Tedarik Tavsiye Listesinin ÇKKV Yöntemleri İle Analizi

\section{Kriterlerin Belirlenmesi, Anket çalışması}

Tedarik kararına etki edecek kriterler Hv.Loj.K.lığında görev yapan toplam 9 uzman personel ile ön bilgilendirme sonrasında yüzyüze yapılan anket neticesinde belirlenmiştir. Etkisi muhtemel 12 ana kriter için katılımcıların 1-5 Likert skalasında (1-önemsiz, 5-çok önemli) önem derecesi atamaları istenmiş her bir kriter için belirlenen önem dereceleri geometrik ortalama ile tek bir sayısal değere dönüştürülmüştür. Önem derecesi 3 ve daha fazla olan 8 kriter çalışmada dikkate alınmıştır. Bu kriterler sırasıyla; "temel konfigürasyonda (TK'da) geçmesi”, "parça bekler (P/B) geçmişi”, "kullanım yeri”, "bakımlarda kullanım durumu", "modernizasyon projelerinde kullanım durumu", "ERRC kodu", "tedarik kaynağı" ve "fiyatıdır".

Anket çalışmasında aynı kriteri ölçümlemek için sorulan soruların kendi aralarında iç tutarlılığı olup olmadığını anlamakta, gözlem sayısı 10'dan küçük olduğu için parametrik olmayan testlerden Cronbach's Alpha testi (Tavakol ve Dennick, 2011) kullanılmıştır. Hesaplamalar SPSS paket programı versiyon 15 ile elde edilmiştir. Ankete uzmanların verdiği yanıtların tutarlılığı $\alpha=0,818$ ile “oldukça güvenilir" kategorisinde yer almıştır.

\section{Kriter Hiyerarşisinin Oluşturulması}

Çalışmada probleme etkisi olduğu belirlenen sekiz ana kriter ve 5 alt kriter için AHP kriter hiyerarşisi Şekil 2'de verilmiştir. Kalitatif kriterlerin ölçeklendirmesi için Hwang ve Yoon'un (1981) 10 puan ölçeği kullanılmıştır. "Fiyat" kriteri için NSN'lerin değerleri öznel olmamasına rağmen, alternatifler arasındaki fiyat verisi arasında çok büyük farklılıklar olmasından dolayı fiyat verileri de ölçeklendirilmiştir.

ERRC (Expendibility, Repairability, Recoverability Code) kodu malzemenin sarf, tamirlik veya teçhizat tipi olduğunu gösteren ve yönetimsel 
kabiliyetleri içeren bir veridir. Sarf malzemeler kullanıldıklarında tükenen; tamirlik malzemeler birlik veya merkez seviyede onarılmak suretiyle ömür devri boyunca tekrar kullanılabilen; teçhizat malzemeler ise kendi başlarına bir görev icra edebilen malzemelerdir. Tamirlik malzemeler genellikle pahalı malzemelerdir. Eğer malzeme teçhizat tipinde (ERRC kodu: $\mathrm{S}$ veya $\mathrm{U}$ ) ise önemi en fazla (ölçek değeri:10); merkez seviyede tamir edilen bir malzeme (ERRC kodu: T-ölçek değeri:7) veya birlik seviyesi tamir edilen bir malzeme ise (ERRC kodu: P-ölçek değeri:4) daha az, sarf(ERRC kodu:N-ölçek değeri:1) malzeme ise en azdır.

NSN'ler için geçmişte yapılan tedarikler ve katalog yönetimi anlayışına uygun olarak bir tedarik kaynağı (SOS-Source of Supply) verisi bulunmaktadır. Takip edilecek her bir tedarik kaynağı belli riskleri barındırmaktadır. Özellikle yurt dışı kaynaklı olan malzemeler için tedarik süresi başta olmak üzere uygulanan prosedürler, tedarikçi nitelik ve sayısı gibi birçok sebepten dolayı önem seviyesi daha fazla; HIBM'lerde (öz kaynak) imal edilecek malzemeler için ise en azdır. Çalışmada farklı tedarik kaynakları için belirlenen ölçek değerleri şu şekildedir: FMS ve NAMSA için:10; ticari kanallar için:7; BAAINBw ve HIBM için: 4 ve diğerleri için 1.

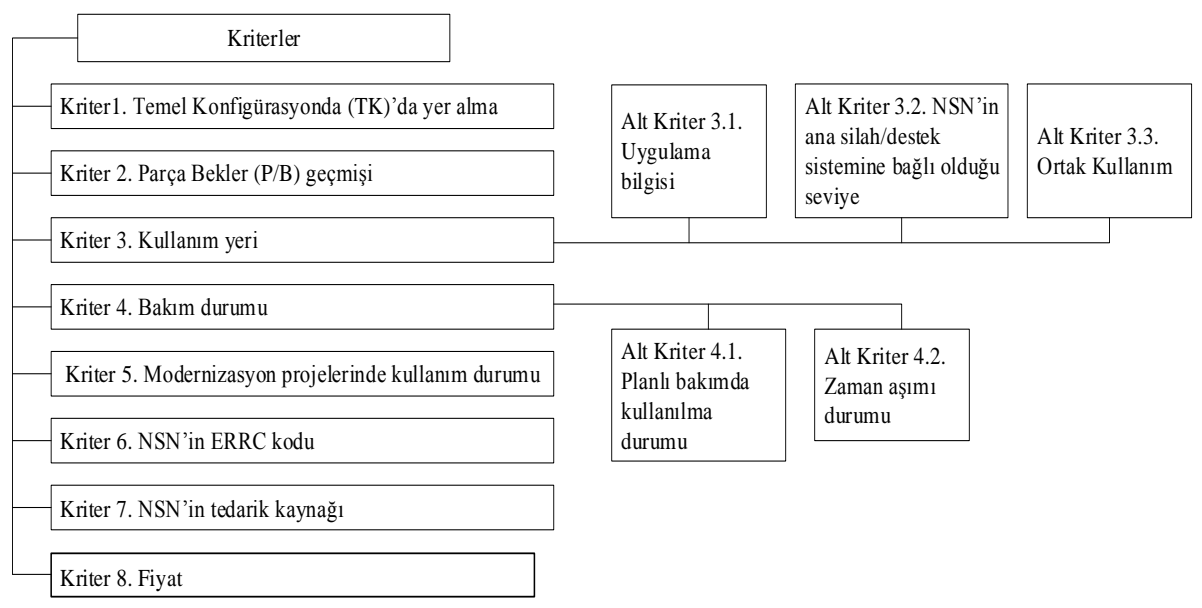

Şekil 2. AHP Kriter Hiyerarşisi 
Hava Kuvvetleri Komutanlığı Malzeme İhtiyaç Planlaması

Tedarik Tavsiye Listesinin ÇKKV Yöntemleri İle Analizi

\section{Kriterlerin AHP Yöntemi ile Ağırlıklarının Tespit Edilmesi}

Dokuz uzman personelin kriter ikili karşılaştırma anketine verdiği yanıtların geometrik ortalaması alınması suretiyle tek bir İkili Karşılaştırma Matrisi (IKM) elde edilmiştir. Örneğin TK'da yer alması ve P/B geçmişi kriterleri için dokuz uzmanın verdiği yanıtlar sırasıyla $3,3,3,3,3,1,1,1,5$ olmak üzere geometrik ortalama $\mathrm{x}=\sqrt[9]{3 \times 3 \times 3 \times 3 \times 3 \times 1} \times 1 \times 1 \times 5=0.2016$ olarak hesaplanmıştır. Kriter ağırlıklarının belirlenmesinde hesaplamalar MS Excel programı ile yapılmıştır. Elde edilen kriter ağılıkları Tablo 2'de verilmiştir. Tutarlılık oranları 0,1 'den küçük olduğundan bu çalışmadaki kriterlerin öncelik değerleri tutarlıdır sonucuna ulaşı1mıştır.

Uzman personelin değerlendirmesinde en etkili kriterlerin malzemenin P/B geçmişi ve kullanım yeri olduğu; değerlendirmeye alınan kriterler içerisinde en az etkili olanın ise malzemenin modernizasyon projelerinde kullanım durumunun olduğu görülmektedir.

Tablo 2. Kriterlerin nihai ağıllık bilgisi

\begin{tabular}{|c|l|l|c|c|}
\hline & Kriter & Alt-Kriter & Ăğ|rlık & $\begin{array}{c}\text { YÜZDE } \\
(\%)\end{array}$ \\
\hline 1 & TK'da yer alması & & 0,1539 & 15,39 \\
\hline 2 & P/B geçmişi & & 0,2583 & 25,83 \\
\hline 3 & \multirow{2}{*}{$\begin{array}{l}\text { Kullanım yeri } \\
(0,2567)\end{array}$} & Tanımlı olan uygulama bilgisi & 0,0816 & 8,16 \\
\cline { 2 - 5 } & Ana sisteme bağlı olduğu seviye & 0,1126 & 11,26 \\
\cline { 2 - 5 } & Ortak kullanım & 0,0625 & 6,25 \\
\hline 4 & $\begin{array}{l}\text { Bakımlarda kullanım } \\
\text { durumu (0,0584) }\end{array}$ & Planlı bakım & 0,0318 & 3,18 \\
\cline { 2 - 5 } & Zaman aşımı & 0,0266 & 2,66 \\
\hline 5 & $\begin{array}{l}\text { Modernizasyon } \\
\text { projelerinde kullanım } \\
\text { durumu }\end{array}$ & & 0,0339 & 3,39 \\
\hline 6 & ERRC kodu & & 0,0780 & 7,8 \\
\hline 7 & Tedarik kaynağ1 & & 0,1107 & 11,07 \\
\hline 8 & Fiyatı & & 0,0501 & 5,01 \\
\hline
\end{tabular}




\section{TOPSIS Yöntemi ile Sıralamanın Belirlenmesi}

Adım 1. Karar matrisinin oluşturulması: Tüm alternatiflerin (NSN'ler) belirlenen 11 kritere göre gösterdiği performansı temsil edecek $\mathrm{A}_{\mathrm{ij}}$ değeri, kriter tanımları ve ölçeklendirme doğrultusunda $5874 \times 11$ boyutlu matris formatında oluşturulmuştur. Her adıma ait hesaplamada ilgili matrisin $15 \times 11$ boyutlu kesitine yer verilmiştir (Tablo 3). Hesaplamalar MS Excel programı ile yapılmıştır.

Tablo 3. $\left[\mathrm{A}_{\mathrm{ij}}\right]$ Karar Matrisinin $15 \mathrm{x} 11$ boyutlu kesiti

\begin{tabular}{|l|l|l|l|l|l|l|l|l|l|l|l|l|}
\hline & $\begin{array}{c}\text { Alternatifler } \\
\text { (NSN) }\end{array}$ & $\begin{array}{c}\text { TK'da } \\
\text { Yer } \\
\text { almas1 }\end{array}$ & $\begin{array}{c}\text { P/B } \\
\text { geçmişi }\end{array}$ & $\begin{array}{c}\text { Uygulama } \\
\text { Bilgisi }\end{array}$ & Seviye & $\begin{array}{c}\text { Ortak } \\
\text { Kullanım }\end{array}$ & $\begin{array}{c}\text { Planlı } \\
\text { Bakım }\end{array}$ & $\begin{array}{c}\text { Zaman } \\
\text { Aşım1 }\end{array}$ & Modernizasyon & ERRC & SOS & Fiyat \\
\hline 1 & 1000931 & 10 & 0 & 10 & 0 & 1 & 0 & 0 & 0 & 1 & 7 & 4 \\
\hline 2 & 1001368 & 0 & 0 & 4 & 1 & 2 & 0 & 0 & 0 & 1 & 10 & 5 \\
\hline 3 & 1001620 & 0 & 0 & 4 & 0 & 1 & 0 & 0 & 0 & 10 & 7 & 4 \\
\hline 4 & 1001659 & 0 & 0 & 7 & 0 & 1 & 0 & 0 & 0 & 7 & 7 & 7 \\
\hline 5 & 1002892 & 0 & 0 & 4 & 1 & 1 & 0 & 0 & 0 & 1 & 7 & 1 \\
\hline 6 & 1008687 & 0 & 0 & 7 & 0 & 2 & 0 & 0 & 0 & 1 & 1 & 2 \\
\hline 7 & 1010475 & 0 & 0 & 7 & 0 & 2 & 0 & 0 & 0 & 1 & 4 & 3 \\
\hline 8 & 1010612 & 0 & 0 & 7 & 0 & 1 & 0 & 0 & 0 & 4 & 7 & 5 \\
\hline 9 & 1011509 & 0 & 0 & 7 & 0 & 1 & 0 & 0 & 0 & 1 & 7 & 4 \\
\hline 10 & 1012068 & 0 & 0 & 4 & 1 & 1 & 0 & 0 & 0 & 1 & 7 & 1 \\
\hline 11 & 1012353 & 0 & 0 & 7 & 0 & 2 & 0 & 0 & 0 & 1 & 10 & 3 \\
\hline 12 & 1013083 & 0 & 0 & 7 & 0 & 1 & 0 & 0 & 0 & 1 & 7 & 3 \\
\hline 13 & 1016278 & 0 & 0 & 10 & 0 & 1 & 0 & 0 & 0 & 1 & 4 & 4 \\
\hline 14 & 1016656 & 0 & 0 & 10 & 0 & 1 & 0 & 0 & 0 & 1 & 4 & 3 \\
\hline 15 & 1019153 & 10 & 1 & 10 & 0 & 1 & 0 & 0 & 0 & 7 & 10 & 8 \\
\hline
\end{tabular}

Tablo 2'de, alternatifler sütununda yer alan 15. Malzeme, 1019153 nolu NSN için TK'da yer alması, uygulama bilgisinin "doğrudan bir silah sisteminde kullanılan malzeme" olması, tedarik kaynă̆ının NAMSA olmasından dolayı ilgili sütun ölçek değerleri 10; geçmişinde bir tane P/B durumu olması ve sadece tek bir sistemde (Sistem-8170934) kullanılıyor olmasından dolayı ilgili sütun ölçek değerleri 1; ERRC kodunun $\mathrm{T}$ olmasından dolayı ilgili sütun ölçek değeri 7; 10.325,16 USD'lik fiyatıyla ilgili sütun ölçek değeri 8; ana silah sistemine 0'ıncı seviyeden bağlı olması ve planlı bakım, zaman aşımı ve modernizasyon içinde yer almamasından dolayı ilgili sütun ölçek değerleri 0 olmak üzere kriter ölçeklendirme formatına uygun olarak belirlenmiştir.

Adım 2. Karar matrisinin normalizasyonu: Karar matrisi Eş. (1) kullanılarak normalize karar matrisi R elde edilmiştir. 
Hava Kuvvetleri Komutanlığı Malzeme İhtiyaç Planlaması

Tedarik Tavsiye Listesinin ÇKKV Yöntemleri İle Analizi

Adım 3. Ağırlıklandırılmış karar matrisinin oluşturulması: AHP yöntemi ile belirlenen kriter ağırlıkları Eşitlik (2)'de kullanılarak ağırlıklandırılmış karar matrisi [V] oluşturulmuştur. Matrise ait kesit Şekil 4'te verilmiştir.

\begin{tabular}{|c|c|c|c|c|c|c|c|c|c|c|c|}
\hline Alternatifler (NSN) & $\begin{array}{c}\text { TK'da yer } \\
\text { alması }\end{array}$ & $\begin{array}{c}\text { P/B } \\
\text { geçmişi }\end{array}$ & $\begin{array}{l}\text { Uygulama } \\
\text { Bilgisi }\end{array}$ & Seviye & $\begin{array}{c}\text { Ortak } \\
\text { Kullanım }\end{array}$ & $\begin{array}{l}\text { Planlı } \\
\text { Bakım }\end{array}$ & $\begin{array}{c}\text { Zaman } \\
\text { Așımı }\end{array}$ & $\begin{array}{c}\text { Moderniz } \\
\text { asyon }\end{array}$ & ERRC & sos & Fiyat \\
\hline 1000931 & 0,0066 & 0,0000 & 0,0015 & 0,0000 & 0,0002 & 0,0000 & 0,0000 & 0,0000 & 0,0003 & 0,0013 & 0,0007 \\
\hline 1001368 & 0,0000 & 0,0000 & 0,0006 & 0,0017 & 0,0005 & 0,0000 & 0,0000 & 0,0000 & 0,0003 & 0,0019 & 0,0009 \\
\hline 1001620 & 0,0000 & 0,0000 & 0,0006 & 0,0000 & 0,0002 & 0,0000 & 0,0000 & 0,0000 & 0,0032 & 0,0013 & 0,0007 \\
\hline 1001659 & 0,0000 & 0,0000 & 0,0010 & 0,0000 & 0,0002 & 0,0000 & 0,0000 & 0,0000 & 0,0022 & 0,0013 & 0,0012 \\
\hline 1002892 & 0,0000 & 0,0000 & 0,0006 & 0,0017 & 0,0002 & 0,0000 & 0,0000 & 0,0000 & 0,0003 & 0,0013 & 0,0002 \\
\hline 1008687 & 0,0000 & 0,0000 & 0,0010 & 0,0000 & 0,0005 & 0,0000 & 0,0000 & 0,0000 & 0,0003 & 0,0002 & 0,0003 \\
\hline 1010475 & 0,0000 & 0,0000 & 0,0010 & 0,0000 & 0,0005 & 0,0000 & 0,0000 & 0,0000 & 0,0003 & 0,0007 & 0,0005 \\
\hline 1010612 & 0,0000 & 0,0000 & 0,0010 & 0,0000 & 0,0002 & 0,0000 & 0,0000 & 0,0000 & 0,0013 & 0,0013 & 0,0009 \\
\hline 1011509 & 0,0000 & 0,0000 & 0,0010 & 0,0000 & 0,0002 & 0,0000 & 0,0000 & 0,0000 & 0,0003 & 0,0013 & 0,0007 \\
\hline 1012068 & 0,0000 & 0,0000 & 0,0006 & 0,0017 & 0,0002 & 0,0000 & 0,0000 & 0,0000 & 0,0003 & 0,0013 & 0,0002 \\
\hline 1012353 & 0,0000 & 0,0000 & 0,0010 & 0,0000 & 0,0005 & 0,0000 & 0,0000 & 0,0000 & 0,0003 & 0,0019 & 0,0005 \\
\hline 1013083 & 0,0000 & 0,0000 & 0,0010 & 0,0000 & 0,0002 & 0,0000 & 0,0000 & 0,0000 & 0,0003 & 0,0013 & 0,0005 \\
\hline 1016278 & 0,0000 & 0,0000 & 0,0015 & 0,0000 & 0,0002 & 0,0000 & 0,0000 & 0,0000 & 0,0003 & 0,0007 & 0,0007 \\
\hline 1016656 & 0,0000 & 0,0000 & 0,0015 & 0,0000 & 0,0002 & 0,0000 & 0,0000 & 0,0000 & 0,0003 & 0,0007 & 0,0005 \\
\hline 1019153 & 0,0066 & 0,0029 & 0,0015 & 0,0000 & 0,0002 & 0,0000 & 0,0000 & 0,0000 & 0,0022 & 0,0019 & 0,0014 \\
\hline
\end{tabular}

Şekil 4. [V] Ağırlıklandırılmış Karar Matrisinin 15x11 boyutlu kesiti.

Adım 4. Pozitif ideal ve negatif ideal çözümlerin belirlenmesi: Eş. (3) ve Eş. (4) kullanılarak çözümlerin bulunması aşamasında, NSN'in ana sisteme bağlı olduğu seviye değerinin küçük olması pozitif ideal çözüme etki ettiğinden bu kriter bir tür maliyet kriteri olarak görülmelidir. $\mathrm{Bu}$ sebeple $\mathrm{A}^{+}$belirlenirken söz konusu kriter için minimum, diğer kriterler için ise maximumlar; $\mathrm{A}^{-}$için ise seviye alt-kriteri için maksimum, diğer kriterler için ise minimumlar dikkate alınmıştır. $\mathrm{Bu}$ doğrultuda; 
$\mathrm{A}^{+}=\{0,0066 ; 0,0975 ; 0,0015 ; 0 ; 0,0202 ; 0,0025 ; 0,0045 ; 0,0113 ; 0,0032 ; 0,0019 ;$ $0,0017\}$

$\mathrm{A}^{-}=\{0 ; 0 ; 0,0001 ; 0,0051 ; 0,0002 ; 0 ; 0 ; 0 ; 0,0003 ; 0,0002 ; 0,0002\}$ belirlenmiştir.

Adım 5. Alternatiflerin ideal ve negatif ideal çözüme uzaklıklarının

hesaplanması: Eş. (5) ve Eş. (6)'ya uygun olarak uzaklıklar hesaplanmıştır.

Hesaplama sonucunda ulaşılan matrise ait kesit Şekil 5'de verilmiştir.

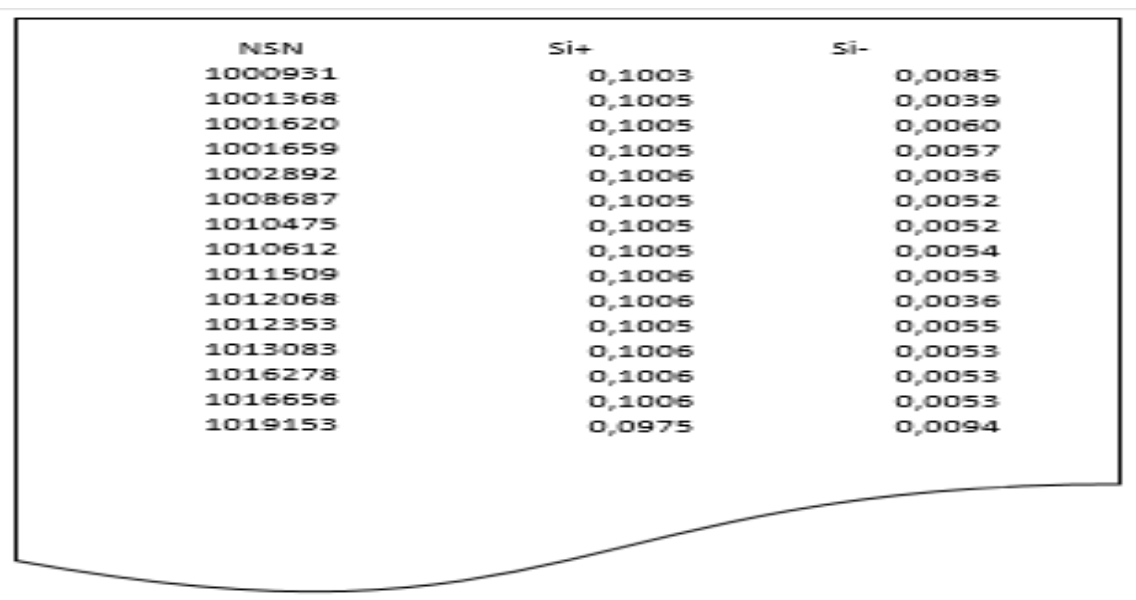

Şekil 5. $S_{i}^{+}$ve $S_{i}^{-}$Matrisine ait kesit

Adım 6. İdeal çözüme göreli yakınlığın hesaplanması: Son adımda Eş. (7)'den yararlanılarak ideal çözüme göreli yakınlık $\left(C_{i}^{*}\right)$ hesaplanmıştır. NSN'ler ideal çözüme göreli yakınlık $\left(C_{i}^{*}\right)$ değerlerine göre sıralanmıştır. Elde edilen sonuçların tam listesi akademik çalışmalarda kullanılmak üzere yazarlardan temin edilebilir.

\section{Sıralama Sonuçlarının Kriter Bazında Analizi}

TOPSIS yöntemi sonuçlar1 ile, MIP'in 02/2014 dönemi tedarik tavsiye listesinde yer alan 5874 kalem malzeme için önem derecesine göre 
Hava Kuvvetleri Komutanlığı Malzeme İhtiyaç Planlaması

Tedarik Tavsiye Listesinin ÇKKV Yöntemleri İle Analizi

gerçekleştirilmiş sıralama elde edilmiştir. Problem tanımı itibariyle tedarik etme/etmeme kararında sıralamanın aynıyla kullanılması hedeflenmemiştir.

Pareto İlkesi'nden hareketle 5874 NSN'in TOPSIS sıralamasındaki ilk 1200 (5874'ün yaklaşık \%20'si) adedi ele alınmıştır. 1200 alternatiften 781 adedinin son 3 y1l içerisinde herhangi bir P/B duruma sebebiyet vermediği; geri kalan 419 adedinin ise en az 1, en fazla 34 defa parça bekler durum yaşanmasına sebep olduğu görülmektedir. Çalışmada kullanılan 5874 NSN'den 462 tanesinin geçmişinde parça bekler oluştuğu göz önüne alındığında; geçmişinde parça bekler olan NSN'lerin \% 90,69'unun sıralamanın ilk 1200'ünde yer aldığ 1 görülmektedir. Alternatiflerden \% 45'inin temel konfigürasyonda yer aldığ 1 , \% 55'inin ise temel konfigürasyon içinde olmadığı görülmektedir. Başka bir ifade ile, 5874 NSN içinde TK'da yer alan 540 adedin tamamı, sıralamanın ilk 1200 sırasında yer bulmuştur. Modernizasyon için gerekli malzeme setinde bulunan 9 NSN'in hepsi listede yer almıştır. Veri setinde ana sisteme bağl1lık seviyesi 0 olan 3527 NSN'in yaklaşık \% 72 'sinin ilk 1200'e girmediği gözlenmiştir. Liste içerisinde her ne kadar önem ölçeği en düşük olsa da, sarf malzemelerin \% 50,3 ile ilk sırada olduğu gözlenmiştir. 5874 NSN'den 5017 tanesinin (\% 85,41) ERRC kodunun N olmasının da bu sonuçta büyük etkisi vardır. Bu durum, genel malzeme kullanım karakteristiklerine uygundur. Yani idame- işletme için en çok sarf malzemelere ihtiyaç duyulmaktadır. Listede yer alan fiyatı düşük bir malzemenin eksikliği önemli bir silah sisteminin kullanım dışı kalmasına neden olabileceği gibi, pahalı bir malzemenin ihtiyaç yokken tedarik edilmesi de kıt kaynakların verimsiz kullanımı sonucunu doğurabilmektedir. İlk 1200 NSN incelendiğinde, liste içerisinde her iki duruma örnek olacak malzemelerin varlığı gözlenmiştir.

Ağırlık olarak en etkin kriter olan P/B geçmiş verisinin sıralamada etkin olduğu görülmektedir. Söz konusu 1200 NSN'in 419 tanesi $(\%$ 34,92) son 3 y1l içerisinde en az 1 defa P/B durumuna sebep olmuştur. \% 15,39 ile ağırlık olarak en önemli ikinci kriter olan TK'da yer alma durumunu 540 NSN ( $\%$ 45) 
sağlamaktadır. Önem derecesine göre üçüncü sırada gelen ana sisteme bağl1 olduğu seviye verisine göre ise, 999 NSN'in (\% 83,25) doğrudan bir silah/destek sistemine bağlı olduğu, ancak ana sisteme 3 veya daha fazla bir seviyeden bağlı olan NSN'lerden sadece 2 tanesinin $(\% 0,17)$ bu listeye girebildiği görülmüştür.

\section{Sıralama Sonuçlarının Kullanıcıların Tedarik Kararları İle Karşılaştırılması}

Karşılaştırma sonuçları, en iyi harbe hazırlık seviyesinin temini ve gereksiz malzemelerin tedariğe bağlanmaması dikkate alınarak aşağıda maddeler halinde özetlenmiştir:

1. Önerilen yaklaşım ile elde edilen sıralamada, ilk 1200 sıraya giren NSN içerisinde; 477 kalem (\% 39,75) NSN için uzman personelin tedarik kararı verdiği, 723 kaleminin $(\% \quad 60,25)$ ise tedariğe bağlanmadığı görülmektedir. Toplamda 5874 kalem NSN'den 902 kalemi için 01 Temmuz 2014 ve verilerin Hv.K.K.lığından teslim alındığı 26 Ağustos 2016 tarihleri arasında farklı gerekçe ve süreler boyunca $\mathrm{P} / \mathrm{B}$ durumu ortaya çıkmıştır. Tedariğe bağlanan 2318 kalem içinde yer alan 353 kalem NSN için, ilerleyen dönemde yine de P/B durumu yaşanmıştır. Sıralamada ilk 1200 'e giren ve uzman personelin tedarik edilmeme yönünde karar aldığı NSN'lerden 73 kalemi $(\%$ 10,1) için ilerleyen dönemde P/B durumu yaşanmıştır.

İlgili dönemde uçakların parça bekler oranının \% 12- \% 13 aralığında olması ihtiyaç belirleme ve kontrat yönetimi alanında personelimizin ne denli dikkatli ve özenli çalıştı̆̆ının bir göstergesidir. Ancak bu çalışma, özünde mevcut durumu iyileştirmeyi hedeflenmiştir.

2. Hv.K.K.lığının harbe hazırlık seviyesinin en iyilenmesi amacında konunun diğer boyutu ise gereksiz malzeme tedariğinin önlenmesidir. $\mathrm{Bu}$ kapsamda gerçek hayatta tedarik kararı verilen malzemelerin \% 22,82'sinin, 01 Temmuz 2014 -26 Ağustos 2016 tarihleri arasında kalan yaklaşı 2 yıl boyunca hiç kullanılmadığı tespit edilmiştir. Sıralamada ilk 1200'e giren NSN'ler arasında bu 
Hava Kuvvetleri Komutanlığı Malzeme İhtiyaç Planlaması

Tedarik Tavsiye Listesinin ÇKKV Yöntemleri İle Analizi

duruma örnek olanların oranı \% 13,7 iken, sıralamaya girmeyenler ise \% 9,12'lik kısma girmektedir. Bir malzemenin tedariğinden sonra kullanılmamış olması, tek başına bu tedarik kararının yanlış olduğunu göstermez. Ancak, söz konusu \% 22,82'lik dilime giren malzemeler içinde hatalı kararların olabileceği değerlendirilebilir. Benzer şekilde, karar vericiler tarafından tedarik etmeme kararı verilmesinden sonra geçen sürede ilgili malzemeye ihtiyaç duyulmadığı durumların da $(\% 77,18)$ tamamının doğru karar olarak değerlendirilmesi uygun olmaz.

Geliştirilen sıralama yaklaşımı, sadece doğru malzemenin tedarik edilmesi konusunda değil; yanlış malzemenin tedarik edilmemesi kararında da ilgili uzman personele katkı sunacağı değerlendirilmektedir.

\section{Sonuç}

Ülke savunmasında hayati bir role sahip olan Hv.K.K.lı̆̆ı, kendisine tahsis edilen bütçe dahilinde envanterinde yer alan silah ve diğer sistemlerin idame ve işletmesini sağlamak için tedarik faaliyetlerini yürütmektedir. Malzeme tedarik tavsiye listeleri, KKP kapsamında HvBS'de çok önemli bir yeri olan Malzeme Yönetim Modulünün bir alt-modulü MIP-KDS ile belirlenmektedir. Yaklaşık 680 000 kalem malzemenin tanımlı olduğu zincir içerisinde ihtiyaç duyulan malzemelere yönelik tavsiye listeleri karar vericilerce değerlendirilmektedir. $\mathrm{Bu}$ çalışmada, karar vericilere değerlendirmelerinde yardımcı olacak bilimsel bir yaklaşım sunulmuştur.

Önerilen yaklaşımın KDS'ye eklenmesi için gerekli mevzuatsal ve yazılımsal hazırlıklar HvBS'nin yazılım yönetim kısımlarınca başlanmış olup yakın gelecekte canlı sistem üzerinde kullanılmaya başlanması planlanmaktadır. Ayrıca çalışmanın, uygulama yapılan sisteme faydasının yanı sıra detaylı literatür araştırması göstermiştir ki, gerek sivil gerekse askerî alanda benzer bir çalışma yer almamaktadır. Bu çalışma, ERP tabanlı MRP sonuçlarının değerlendirilmesinde 
karar destek sistemine yardımcı olacak nitelikte ÇKKV yaklaşımlarını kullanması ile literatüre katkı sağlamaktadır.

Literatürde AHP ve TOPSIS yöntemi ile ilgili kritiklere Arıkan ve Çıtak'ın (2017) çalışmasından erişilebilir. Burada gerçekleştirilen çalışma açısından değerlendirilmek üzere, temel olarak AHP ile ilgili ilk kritik, kriter hiyerarşisindeki seviye sayısı arttığında yöntemin uygulanabilirliğinin kısıtlanabileceğine yöneliktir. Gerçekleştirilen çalışmada, AHP yöntemi alternatiflerin seçimi problemi için değil, kriterlerin ağırlıklarının belirlenmesi için kullanılmıştır. Dolayısıyla ikili karşılaştırmalar sadece kriterler için gerçekleştirilmiştir. AHP ile ilgili ikinci kritik ise sira tersi (rank reversal) problemidir. Bu problem, yeni bir kriter veya alternatif eklenmesi halinde önem değerlerinin temin edilmesindeki zorluktan kaynaklanmaktadır. Sıra tersi problemi TOPSIS yönteminin de literatürde varolan kritiğidir. Gerçekleştirilen çalışma açısından, bütünleşik yöntem, sistemde halihazırda kullanılan bir KDS'ye yine bir yazılım yardımıyla ekleneceğinden kriterlerde ya da alternatiflerdeki değişimler söz konusu olduğunda problem tolere edilebilecektir.

Geleceğe yönelik olarak, Mİ'in sonuçlarından onarım tavsiye listeleri için benzer bir çalışma değerlendirilebileceği öngörülmüştür. Ayrıca, faydalanılan bütünleşik yöntem sübjektif olduğundan duyarlılık analizlerinin geliştirilecek KDS sistemi içerisinde değerlendirilmesi uygulamaya katkı sağlayacaktır.

\section{Teşekkür}

Yazarlar, çalışmanın değerini arttıran kıymetli kritikleri için hakemlere derin teşekkürlerini sunar. 
Hava Kuvvetleri Komutanlığı Malzeme İhtiyaç Planlaması

Tedarik Tavsiye Listesinin ÇKKV Yöntemleri İle Analizi

\section{Extended Summary}

\section{Introduction}

The ability of businesses to sustain their assets and adapt to today's increasingly competitive conditions is only possible through the rapid and accurate processing and management of high-level information. Enterprise Resource Planning (ERP) systems serve the purpose that rapid and accurate processing and management of high-level information. with an integrated data/information management system.

Businesses that utilize Enterprise Resource Planning (ERP) use many quantitative and qualitative variables such as product delivery times, customer satisfaction, and operating expenses as criteria to eavluate the achieving levels of their goals. These variables are important for the military industry too, but additional variables are needed due to the specific objectives of the defense sector. The most important one of these is the level of preperadness of war which refers to the situation of military presence in terms of any military unit, personnel and equipment. Matter preparation level, which is a qualitative variable; varies in time, location and terms of procurement. This variability makes it difficult to assess military decisions. Moreover, when the field of activity in the defense sector is military-aerospace, problems with material supply can have critical consequences for both financial and strategic security.

Turkish Air Force utilizes a Decision Support System (DSS) that ensure the material requirement planning (MRP). The material-purchase-list established by the DSS is examined by the specialist staff to make the supply decision. The purpose of the study is to provide a scientific approach which will guide decision makers in the examination activity, by ranking the MRP results according to the importance level in order to give the most accurate procurement decision. 


\section{Literature Review}

Literature research has been restricted to studies in the Science Citation Index (SCI), which contains international journals and scientific studies. A detailed literature search on procurement decisions made using the Multiple Criteria Decision Making (MCDM) Techniques can be accessed from Yagli (2017). In the field of military decision-making, only Wang et al. (2008) and Sanchez-Lozana et al. (2015) uses the AHP and TOPSIS approach integrally. But these two studies addressed the issue of military aircraft selection.

Within the above research constraints, neither in the civilian nor in the military field there is a study which utilizes the MCDM Techniques to aid the DSS in evaluating ERP based MRP outcomes. With these properties, the current study contributes to the literature.

\section{Metodology}

The techniques of AHP and TOPSIS that are integrated in the proposed approach are briefly reviewed in this section.

\section{AHP (Analytical Hierarchy Process)}

AHP was developed by Thomas L. Saaty in 1965. The steps of the technique can be summarized as follows (Saaty, 1990):

Step 1. The MCDM problem is defined and its goal is identified.

Step 2. The decision hierarchy is decomposed.

Step 3. The pair-wise comparison matrix is constructed.

Step 4. The relative weights are produced.

Step 5. The consistency ratio (CR) is calculated. The recommended consistency ratio is less than or equal to 0.1 .

TOPSIS (Technique for Order Preference by Similarity to the Ideal Solution) TOPSIS, developed by Hwang and Yoon (1981). The steps of the technique based on Hwang and Yoon (1981) and Shih et al. (2007) are as follows: TOPSIS Step 1. Construct the decision matrix D. 
Hava Kuvvetleri Komutanlığı Malzeme İhtiyaç Planlaması

Tedarik Tavsiye Listesinin ÇKKV Yöntemleri İle Analizi

TOPSIS Step 2. Construct the normalized decision matrix R

TOPSIS Step 3.Calculate the weighted normalized decision matrix.

TOPSIS Step 4. Determine the ideal $\left(A^{+}\right)$and negative ideal $\left(A^{-}\right)$ solutions.

TOPSIS Step 5. Calculate the separation measures $\left(\mathrm{S}_{\mathrm{k}}^{+}, \mathrm{S}_{\mathrm{k}}^{-}\right)$.

TOPSIS Step 6. Calculate the relative closeness to the ideal solution $\left(\mathrm{C}_{\mathrm{k}}^{+}\right)$ and rank the preference order.

\section{System and Problem Definition}

Air Logistics Command (Hv.Loj.K.lı̆g $)$ is responsible of fulfillment of supply, maintenance, transportation, fortification and other logistic activities and also calculation, procurement, infrastructure and facilities to meet the needs of the organization. The procurement list (planned order) issued by the MRP is examined by the specialist personnel in determining the material requirements for administration and management, and a decision is made whether or not to supply. There are no information about rank orders or groups for the materials in the list. The staff prioritize and evaluate the planned orders based on their own knowledges and experiences. The fact that compensating for erroneous procurement decisions takes a long time and are more costly than when they are taken in proper time, increases the need and importance of decision makers to make their procurement decisions more healthier in time.

\section{Application}

For the solution of the problem, the integrated steps of the AHP-TOPSIS methods has been carried out. The utilized integrated technique provides opportunity for experts to examine the purchased items primarily that might be ignored via traditional approach; prevent to exceed the possible deadline for waiting parts and use scarce resources more effective. Criteria that will influence the decision of procurement are determined by a questionnaire study. AHP criteria hierarchy was constructed. Hwang and Yoon's (1981) "10 point scale” was utilized 
for scaling qualitative criteria. Weights of criteria were determined by AHP method. The ranking order of alternatives (materials placed in the procurement list) was obtained by TOPSIS Technique. The ranking order was evaluated based on each criterion. The obtained order was compared with the Staff's decisions in the considered past period.

\section{Conclusion}

Having a vital role in the defense of the country, Air Logistic Commands carries out procurement activities to ensure the management and operation of weapons and other systems in its inventory within the budget allocated to it. This study aims to keep the procurement decisions in the most efficient level. It is determined that by providing the proposed scientific approach the specialist staff could be able to make effective decisions to evaluate the procurement list within a limited time they have, and it could be possible to reach the aim of reducing human errors. For the future, a similar study can be evaluated for the repair lists from the results of the MRP module.

\section{Kaynakça}

\section{Kitaplar}

Hwang, C.L. and Yoon, K., (1981). Multi Attribute Decision Making Methods and Applications A State of The Art Survey. Springer-Verlag, Berlin.

\section{Makaleler}

Arıkan F., Çıtak Ş. (2017), Multiple Criteria Inventory Classification in an Electronics Firm, International Journal of Information Technology \& Decision Making, Vol. 16, No. 2 (2017) 315-331. 
Hava Kuvvetleri Komutanlığı Malzeme İhtiyaç Planlaması

Tedarik Tavsiye Listesinin ÇKKV Yöntemleri İle Analizi

Arıkan F., Küçükce Y.S (2012), Satın Alma Faaliyeti İçin Bir Tedarikçi SeçimiDeğerlendirme Problemi Ve Çözümü, Gazi Üniversitesi, Mühendislik Mimarlık Fakültesi Dergisi, 27(2), 255-264.

Arslan, G. and Aydın, Ö. (2009). A new software development for Fuzzy Multicriteria decision-making. Technological and Economic Development of Economy, 15(2), 197-212.

Ayag Z., Ozdemir R.G. (2007), An intelligent approach to ERP software selection through fuzzy ANP, International Journal Of Production Research 45, (10), 2169-2194.

Aydoğan, E.K., Gencer, C. and Aytürk, S. (2009). Evaluation of a Light Machine Gun Using Analytic Network Process. Defence Science Journal, 59(3), $273-$ 283.

Can Ş., Arikan F. (2014) Multi Criteria Subcontractor Selection Problem and its Solution for a Defence Industry Firm, Journal of the Faculty of Engineering and Architecture of Gazi University, 29 (4), 645-654, 2014.

Chang, J.R., Cheng, C.H. and Chen, L.S. (2007). A fuzzy-based military officer performance appraisal system. Applied Soft Computing, 7(3), 936-945.

Cheng, C.H. (1996). Evaluating naval tactical missile systems by fuzzy AHP based on the grade value of membership function. European Journal of Operational Research, 96, 343-350.

Cheng, C.H. (1999). Evaluating weapon systems using ranking fuzzy numbers. Fuzzy Sets And Systems, 107(1), 25-35.

Cheng, C.H., Yang, K.L. and Hwang, C.L. (1999). Evaluating attack helicopters by AHP based on linguistic variable weight. European Journal of Operational Research, 116, 423-435.

Farahani, R.Z., Asgari, N. (2007). Combination of MCDM and covering techniques in a hierarchical model for facility location: A case study. European Journal of Operational Research, 176 (3), 1839-1858. 
Gazibey, Y., Kantemir, O. and Demirel, A. (2015). Interaction Among the Criteria Affecting Main Battle Tank Selection: An Analysis with DEMATEL Method. Defence Science Journal, 65(5), 345-355.

Gürbüz, T., Alptekin, S.E. and Alptekin, G.I. (2012). A hybrid MCDM methodology for ERP selection problem with interacting criteria. Decision Support Systems, 54, 206-214.

Jiang, J., Li, X., Zhou, Z.J., Xu, D.L. and Chen, Y.W. (2011). Weapon System Capability Assessment under uncertainty based on the evidential reasoning approach. Expert Systems with Applications, 38, 13773-13784.

Kılıç, H.S., Zaim, S. and Delen, D. (2014). Development of a hybrid methodology for ERP system selection: The case of Turkish Airlines. Decision Support Systems, 66, 82-92.

Leeneer, I.D., Pastijn, H. (2002). Selecting land mine detection strategies by means of outranking MCDM techniques. European Journal Of Operational Research, 139(2), 327-338.

Lin, K.P., Hung, K.C. (2011). An efficient fuzzy weighted average algorithm for the military UAV selecting under group decision-making. Knowledge-Based Systems, 24, 877-889.

Lu, W.M., Wang, T.C.(2011). A fuzzy multi-criteria model for the industrial cooperation program transaction strategies: A case in Taiwan. Expert Systems with Applications, 38(3), 1490-1500.

Saaty, T.L. (1990). How to Make a Decision : The Analytic Hierarcy Process. European Journal of Operation Research, 48, 9-26.

Sanchez-Lozano, J.M., Serna, J. and Dolón-Payán, A. (2015). Evaluating military training aircrafts through the combination of multi-criteria decision making processes with fuzzy logic. A case study in the Spanish Air Force Academy. Aerospace Science and Technology, 42, 58-65. 
Hava Kuvvetleri Komutanlığı Malzeme İhtiyaç Planlaması

Tedarik Tavsiye Listesinin ÇKKV Yöntemleri İle Analizi

Schubert, J., Hörling, P. (2014). Preference-based Monte Carlo Weight Assignment for Multiple-criteria Decision Making in Defense Planning. 17th International Conference on Information Fusion (FUSION) Location: Salamanca, Ispanya.

Shen Y.C., Chen P.S., and Wang, C.H. (2016), A study of enterprise resource planning (ERP) system performance measurement using the quantitative balanced scorecard approach, Computers In Industry, 75 , 127-139.

Shih, H-S., Shyur, H-J. and Lee, S.E., (2007) "An extension of TOPSIS for group decision making", Mathematical and Computer Modeling, 45, 801-813.

Tavakol, M. and Dennick, R. (2011). Making sense of Cronbach's Alpha. International Journal of Medical Education. , 53-55.

Wang, J., Fan, K., Su, Y., Liang, S. and Wang, W. (2008). Air Combat Effectiveness Assessment of Military Aircraft Using a Fuzzy AHP and TOPSIS Methodology. 7th International Conference On System Simulation And Scientific Computing Asia Simulation Conference, 1(3), 655-662.

Wang, T.C. (2012). The interactive trade decision-making research: An application case of novel hybrid MCDM model. Economic Modelling, 29, 926-935.

\section{Tezler}

Yağlı, U. (2017) Hava Kuvvetleri Komutanlığı Malzeme İhtiyaç Planlaması Tedarik Tavsiyesi Sonuçlarının ÇÖKV Yöntemleri İle Analizi, Gazi Ünv., Fen Bilimleri Enstitüsü, Basılmamış Yüksek Lisans Tezi, Haziran 2017. 